\title{
Broken handle cord of impacted biliary basket - rescue by cholangioscopy with laser lithotripsy
}

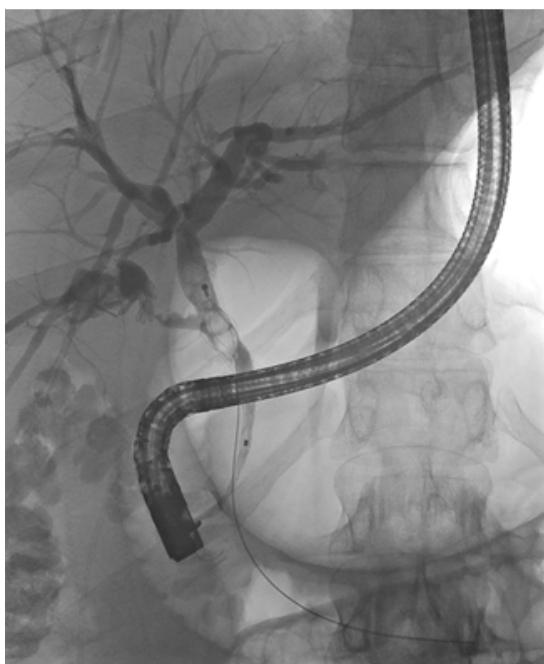

- Fig. 1 Cholangiogram showing the impacted biliary basket with the two entrapped stones while the rest of the wire trails free in the duodenum.

Endoscopic retrograde cholangiopancreatography (ERCP) is the gold standard procedure for the treatment of bile duct stones, and most stones are successfully removed with accessories such as biliary baskets or extraction balloons. Impaction of a biliary basket is not an uncommon complication of this procedure, being reported in $0.8 \%-5.9 \%$ of cases. Mechanical lithotripsy usually solves the problem by crushing the stone, followed by extraction of the stone fragments. However, on rare occasions, fracture of the basket occurs during mechanical lithotripsy, and this can pose a special management problem, depending on where the breakage occurs [1 - 3]. We report the successful management of an impacted biliary basket after breakage of the basket handle cord during extra-endoscopic mechanical lithotripsy.

A 35-year-old man, who had undergone early laparoscopic cholecystectomy in a small regional hospital 1 month before, presented with jaundice and upper right quadrant pain on admission. Laboratory tests revealed obstructive jaundice with

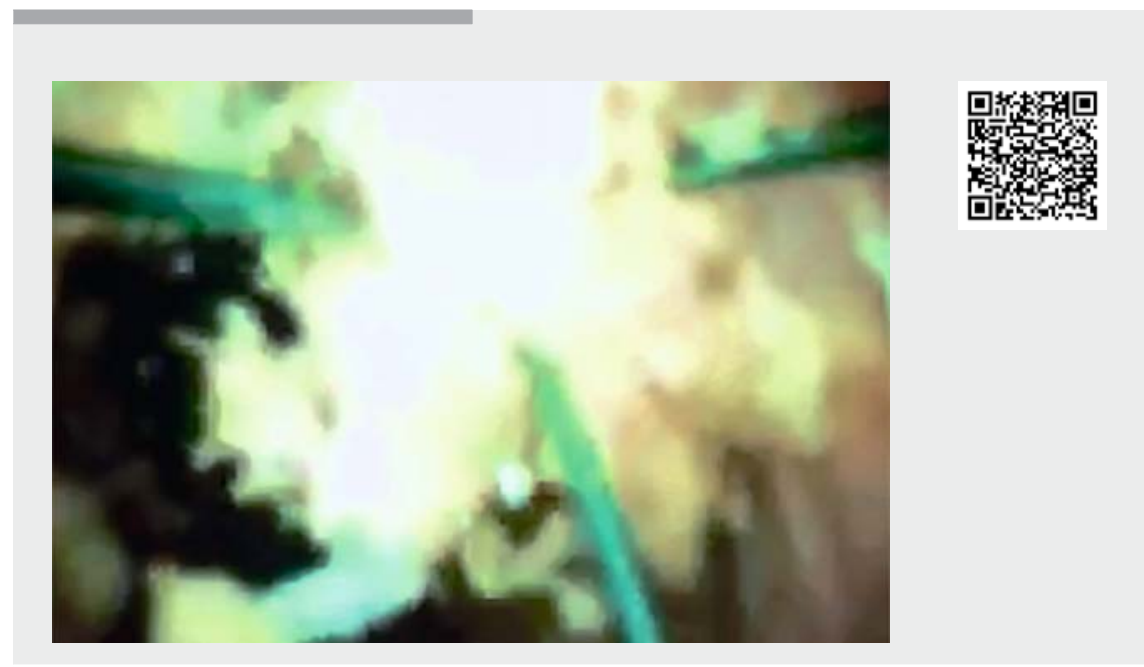

Video 1 Cholangioscopy followed by laser lithotripsy of the entrapped stone-basket complex. Once the stones had been successfully crushed, the basket was withdrawn using the forceps accessory.
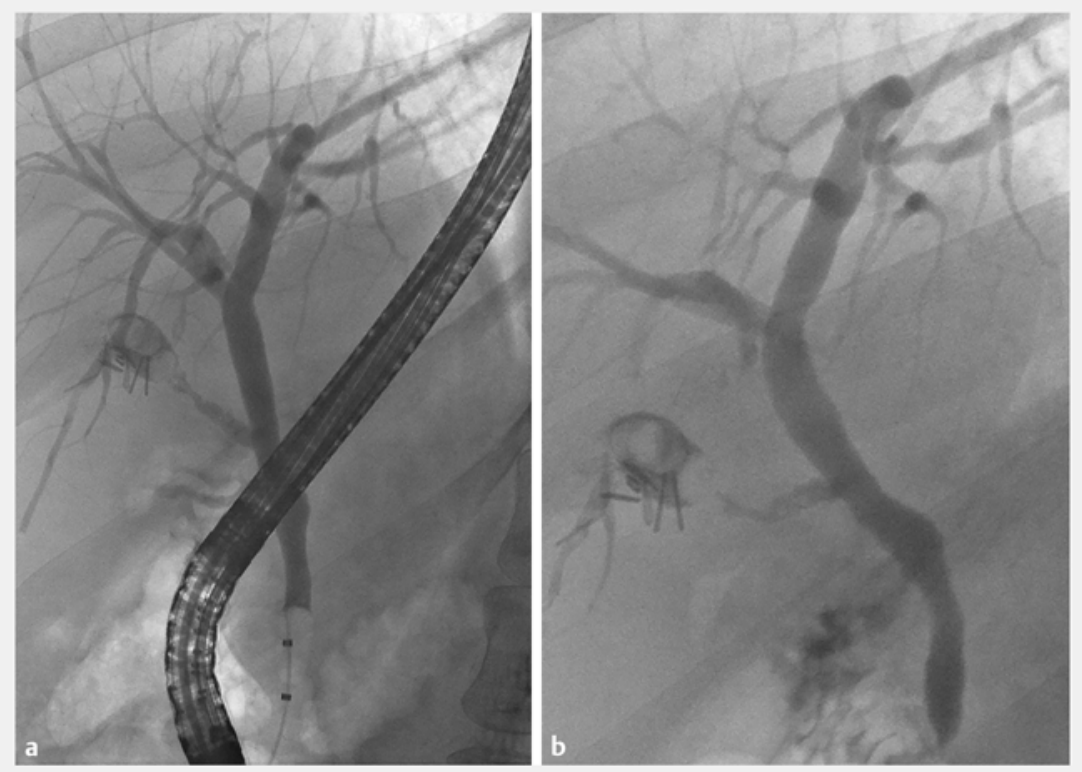

Fig. 2 a Negative occlusion cholangiogram. b Normal cholangiogram after retrieval of the duodenoscope.

raised $\mathrm{y}$-glutamyl transpeptidase ( $\mathrm{YGT}$ ) and alkaline phosphatase (ALP) and a total bilirubin concentration of $11.11 \mathrm{mg} /$
dL. Apart from a mildly dilated common bile duct (CBD) with stones, computed tomography of the abdomen revealed no 
abnormalities. ERCP was undertaken as part of the treatment plan.

After successful cannulation and sphincterotomy, two small stones were captured with a $20-\mathrm{mm}$ basket but could not be extracted due to the discrepancy between the size of the stones and the small diameter of the distal CBD; in addition, it proved impossible to retrieve the stones from the basket. For this reason, extraendoscopic mechanical lithotripsy using a Soehendra lithotriptor was undertaken, but the handle cord broke $15 \mathrm{~cm}$ from the basket and the basket-stone complex remained impacted, with the cord end flapping freely in the lumen of the duodenum ( $\triangleright$ Fig. 1).

The next day the patient underwent ERCP with cholangioscopy and laser lithotripsy, and the stones were crushed within the impacted biliary basket; this was followed by successful extraction of the basket together with the fragments ( $\vee$ Video 1$)$. The final occlusion cholangiogram showed the CBD to be cleared ( Fig.2).

Endoscopy_UCTN_Code_CPL_1AK_2AC

\section{Competing interests}

The authors declare that they have no conflict of interest.
The authors

Tomislav Bokun ${ }^{1}$, Mario Tadic ${ }^{1}$, Admir Kurtcehajic $^{2,3}$, Ivica Grgurevic ${ }^{1}$, Milan Kujundzic

1 Department of Gastroenterology, University Hospital Dubrava, Zagreb, Croatia

2 Gastroenterology Unit, Department of Internal Medicine, Plava Poliklinika Medical Center, Tuzla, Bosnia and Herzegovina

3 Medical Faculty, University of Tuzla, Tuzla, Bosnia and Herzegovina

\section{Corresponding author}

\section{Admir Kurtcehajic, MD}

Plava Poliklinika Medical Center, 3rd Tuzlanska Brigada No. 7, 75000 Tuzla, Bosnia and Herzegovina Fax: +387-35-393111

admircg7@gmail.com

\section{References}

[1] Attila T, May GR, Kortan P. Nonsurgical management of an impacted mechanical lithotriptor with fractured traction wires: endoscopic intracorporeal electrohydraulic shock wave lithotripsy followed by extra-endoscopic mechanical lithotripsy. Can J Gastroenterol 2008; 22: 699-702

[2] Khawaja FI, Ahmad MM. Basketing a basket: A novel emergency rescue technique. World J Gastrointest Endosc 2012; 4: 429-431

[3] Borgaonkar M. Impacted biliary basket. Gastrointest Endosc 2005; 62: 474
Bibliography

Endoscopy 2020; 52: E459-E460

DOI $10.1055 / a-1167-0904$

ISSN 0013-726X

published online 19.5.2020

(c) 2020. Thieme. All rights reserved.

Georg Thieme Verlag KG, Rüdigerstraße 14,

70469 Stuttgart, Germany

\section{ENDOSCOPY E-VIDEOS}

https:/|eref.thieme.de/e-videos

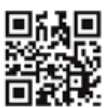

Endoscopy E-Videos is a free access online section, reporting on interesting cases and new

techniques in gastroenterological endoscopy. All papers include a high quality video and all contributions are freely accessible online.

This section has its own submission website at https://mc.manuscriptcentral.com/e-videos 